\title{
Patrolling and scent-marking behavior in Japanese bumblebee Bombus ardens ardens males: alternative mating tactic?
}

\author{
Ken-ichi Harano ${ }^{1,2}$, Ryohei $\mathrm{KuBO}^{1}$, Masato OnO ${ }^{1,2}$ \\ ${ }^{1}$ Honeybee Science Research Center, Tamagawa University, Machida, Tokyo 194-8610, Japan \\ ${ }^{2}$ Graduate School of Agriculture, Tamagawa University, Machida, Tokyo 194-8610, Japan
}

Received 4 April 2017 - Revised 20 June 2017 - Accepted 26 July 2017

\begin{abstract}
Previous reports note that males of the Japanese bumblebee Bombus ardens ardens perform nest surveillance to mate with new queens. Here, we report that males of this species also perform patrolling and scentmarking for mating. We observed that many $B$. ardens ardens males fly together from May to June in circular paths through a wooded area in Tokyo, Japan. The flight activity is bimodal with peaks in the morning and late afternoon. When tethered new queens were presented at a focal point, males approached, touched, or grabbed them but ignored them at a foraging site. Males performed scent-marking on tree leaves only in the early morning (05:30 to 07:30), and compounds from the labial gland of $B$. ardens ardens males were detected on a scent-marked leaf. Based on these findings and previous reports, we conclude that males of this species have at least two mating tactics or strategies: nest surveillance and patrolling.
\end{abstract}

\section{male / patrolling / premating behavior / reproductive strategy / sex pheromone}

\section{INTRODUCTION}

Some male animals have behavioral variations providing better mating access to females (reviewed by Alcock 2013; Gross 1996). These behavioral variations may arise from different genotypes and are recognized as alternative strategies (Shuster and Wade 1991). In other animals, they are caused by environmental factors and are referred to as alternative tactics (e.g., Thornhill 1981; Emlen 1994). In this case, the animals are considered to use a single conditioned strategy in which different tactics occur, depending on envi-

Electronic supplementary material The online version of this article (doi:10.1007/s13592-017-0534-2) contains supplementary material, which is available to authorized users.

Corresponding author: K. Harano, kharano@lab.tamagawa.ac.jp Manuscript editor: James Nieh ronmental factors. The conditioned strategy is typically found in animals where males fight for access to females. Since the likelihood of gaining access to females and mating may be determined by the physical ability of males, disadvantaged males may avoid direct combat and adopt alternative tactics, such as sneaking (e.g., Cook 1990) and mimicking females (e.g., Forsyth and Alcock 1990).

Bumblebee males show different premating behaviors, depending on species. At least three distinct patterns have been reported (Goulson 2003): (1) nest surveillance: males wait in front of the nest entrance and catch new queens leaving the nest, (2) perching: males form a territory and attract virgin queens with a pheromone deposited on their perch, and (3) patrolling: males fly along a circuitous path and deposit a pheromone on objects such as leaves, twigs, and rocks along the path to attract virgin queens. Males using nest surveillance and perching may engage in physical 
combat to defend a territory or good position for waiting for queens (Villalobos and Shelly 1987; Kindl et al. 1999). Usually, males do not fight during patrolling. Only one type of premating behavior has been reported in most bumblebee species, so the possibility of conditioned premating strategy where males use distinct mate-locating tactics depending on environmental factors has not been considered.

Males of Bombus ardens ardens Smith (Hymenoptera; Bombinae), a common bumblebee distributed widely across Japan except Hokkaido and Okinawa, are reported to use nest surveillance to mate with queens (Katayama 1964; Ono and Wada 1996). Colonies of this species produce males and new queens from late spring to early summer (May-June, in central Japan). A queen starts underground hibernation before midsummer (July-August) after mating with a single male (Kokuvo et al. 2009). Katayama (1964) observed that several $B$. ardens ardens males hover around the entrance of a conspecific nest and mate with new queens flying out from the nest. An additional 10 males were found to mate with queens in the nest. A similar congregation of males and mating with departing new queens in front of the nest was also observed by Ono and Wada (1996, plate D). Since there is no reported other premating behavior, nest surveillance is generally regarded as the mating strategy of this species.

On the other hand, Kubo and Ono (2010) found that $B$. ardens ardens males produce speciesspecific volatiles in their labial gland (LG) with citronellol as a major compound and citronellal and citronellyl acetate as minor compounds. The secretion from LG is believed to serve as sex pheromones in the patrolling and perching strategies of other species (Kullenberg et al. 1973; Bergman and Bergström 1997; Kindl et al. 1999). This finding suggest that $B$. ardens ardens males may also use a patrolling or perching tactic in addition to nest surveillance. Males of some species which show perching strategy have distinct large compound eyes (Goulson 2003), but $B$. ardens ardens males are not with such a morphological character.

In 2015 and 2016, we found many B. ardens ardens males exhibiting a patrolling-like behavior in a wooded area. This study describes this behavior and discusses whether this is an alternative mate location tactic in $B$. ardens ardens .

\section{MATERIALS AND METHODS}

\subsection{Study site}

The behavior of $B$. ardens ardens males was observed in a hilly, wooded area (Fig. 1) on the campus of Tamagawa University $\left(35^{\circ} 34^{\prime} \mathrm{N}, 139^{\circ}\right.$ $28^{\prime}$ E), Tokyo, Japan in May-June, 2015-2017. The area is almost entirely covered with high trees
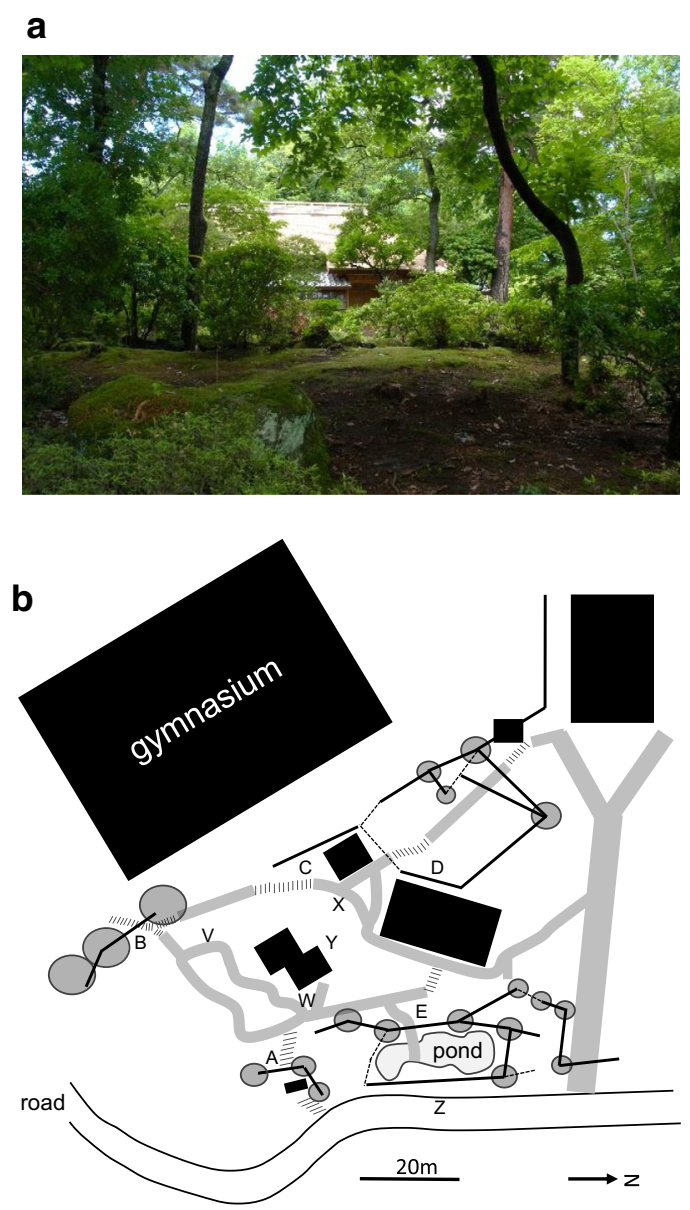

Figure 1. View (a) and schematic representation (b) of study site. Building (filled square). Flight path where more than 10 male passings were observed for $5 \mathrm{~min}$ (bold line). Flight path where fewer than 10 male passings were observed for $5 \mathrm{~min}$ (dotted line). Trees or bushes used as focal points (grayed circle). 
such as Quercus serrata, Quercus acutissima, Prunus spp., and Acer spp. Bushes and midstory trees such as Pieris japonica, Rhododendron indicum, Rhododendron pulchrum cv. Oomurasaki, Aucuba japonica, and Camellia japonica are found under the high canopy.

\subsection{Survey of flight path}

Males of $B$. ardens ardens flying in the study site in early June 2015 appeared to follow particular routes. First, we paint-marked some males and tried to follow them to determine the flight path but failed because the flight was too fast to recognize the marking and they were often lost in bushes. Consequently, we mapped only major paths along which males flew frequently. The number of males passing through the path was counted for $5 \mathrm{~min}$ to quantify the path usage degree. At several points on the flight path (sites A-E in Fig. 1b), the number of passing by males was counted five times for consecutive 25-min periods. To examine whether flights were concentrated on these paths, the number of male passings was also counted in the same manner at five locations near but off the path (sites $\mathrm{V}-\mathrm{Z}$ in Fig. $1 b)$.

As described below, males had several "focal points" (Goulson 2003; also known as "approaching place" (Svensson 1979) on the flight path where they slowed down and showed a brief zig-zag flight toward the leaves of a tree. Six males were captured at three distinct focal points in the study site and paint-marked on their thoraxes for individual identification. Later, the interval between visits to the focal point and the flight direction was recorded to determine whether these males were flying a circuitous route as reported in other patrolling Bombus species (e.g., Svensson 1979).

\subsection{Survey of flight and scent-marking activities}

The timing of the appearance of flying males and changes in the number with time were investigated from 12 May to 27 June 2016. During this period, the number of males passing for 5 min was recorded between 11:00 and 13:00 at sites $\mathrm{A}$ and
B (Fig. 1b) every day except 13-17 May. The air temperature and relative humidity were also recorded at each observation using a digital thermohygrometer (Ondotori TR-72Ui; T\&D Corp., Tokyo, Japan).

Changes in male flight activities within a day were investigated by counting passing males at sites A and B every 30 min or $1-2 \mathrm{~h}$ on 24 May and 10 June 2016. We first noticed males scentmarking leaves on May 24, and recorded this behavior on June 10. Three Pieris japonica and one Rhododendron pulchrum cv. Oomurasaki trees growing in a confined area at site A were selected because these trees were used as focal points by several males on previous days and males of other Bombus species have been reported (Svensson 1979) to scent-mark objects at focal points. The number of males scent-marking these trees during a 15 -min period was counted in every time frame.

\subsection{Male response to tethered queens}

If the patrolling behavior is related to mate searching, we should expect patrolling males to try to mate with queens. To examine the male response to queens, tethered queens were presented at a focal point. Three B. ardens ardens new queens were caught on flowers on 28 and 31 May 2016 and kept individually in plastic containers (dia. $9.5 \mathrm{~cm} \times 8 \mathrm{~cm}$ ) with $60 \%$ sucrose solution until the experiments were carried out from 2 to 5 June 2016. Their wings were clipped to prevent absconding during the experiment. One of the three queens was hung from a branch of P. japonica at site A using fishing line (length, ca. $50 \mathrm{~cm}$ ) tied between the thorax and abdomen. This tree had been used as a focal point by several males. The response of males flying within $50 \mathrm{~cm}$ of the tethered queen was classified into five categories and recorded for a 10-min observation period. The male response categories: (1) mating when male inserted their genitalia into the queen, (2) grabbing when male held the queen with their legs but did not mate, (3) contacting when touching but not grabbing the queen, (4) approaching when they turned toward the queen $(<10 \mathrm{~cm})$ or hovered directly facing the queen, and (5) ignoring when showing none of above responses. If a 
male showed more than one response category, the response with the higher degree was recorded. Only one queen was presented on 1 day.

To compare the mating motivational state, the responses of males to tethered queens were also observed at a foraging site about $200 \mathrm{~m}$ from the study area. The same queens were tethered from a branch of a flowering Ligustrum japonicum tree (height, approx. $3 \mathrm{~m}$ ) where many males were feeding on flowers at the same time. The behavioral responses of males were recorded for $10 \mathrm{~min}$ per queen as at the study site. Assays of the patrolling and foraging sites were carried out on the same day for one queen.

\subsection{GCMS analysis}

We examined whether compounds from male LG were detected on scent-marked objects. $P$. japonica leaves $(N=13)$ that had been seen to be scent-marked by $B$. ardens ardens males were collected at site A (Fig. 1b) at 05:00-07:30 on 1 June 2016 and 30 May and 6 June 2017. Other leaves $(N=13)$ were collected at the same time from different $P$. japonica trees that were not used as a focal point as unmarked samples. Immediately after collection, the leaves were placed individually in a $20-\mathrm{mL}$ glass vial sealed with aluminum foil.

To compare compounds detected on the leaves, compounds from the LG of a $B$. ardens ardens male were also analyzed. A B. ardens ardens male was collected at the study site and killed in a freezer at $-20^{\circ} \mathrm{C}$ before analysis. The LGs were dissected from the head and stored in a 4-mL vial sealed with aluminum foil. Only a single male was sacrificed to show the chemical profile of volatiles from LGs because that has already been documented elsewhere (Kubo and Ono 2010).

Volatiles were collected from the scent-marked leaf, unmarked leaf, and crushed LG by SPME headspace sampling for $20 \mathrm{~min}$ in the laboratory. A SPME device (Supelco Co.) with a fused-silica fiber coated with polydimethylsiloxane (PDMS, $100-\mu \mathrm{m}$ thickness) was used.

All samples for GCMS were analyzed using a gas chromatograph-mass spectrometer (GCMSQP2010; Shimadzu Co.) with electron ionization. The injection port had a narrow-bore $(0.75-\mathrm{mm}$ id) glass liner to minimize peak broadening. A DB-5MS column $(60 \mathrm{~m} \times 0.32 \mathrm{~mm}$ id, $0.25-\mu \mathrm{m}$ thickness; J\&W Scientific Co.) was used to separate components. A splitless injector mode $\left(250^{\circ} \mathrm{C}\right)$ and $\mathrm{He}$ carrier gas were used. The carrier flow was $1.7 \mathrm{~mL} / \mathrm{min}$, and the interface temperature was $260{ }^{\circ} \mathrm{C}$. The column temperature was held at $50{ }^{\circ} \mathrm{C}$ and then increased to $250{ }^{\circ} \mathrm{C}$ at $5{ }^{\circ} \mathrm{C} / \mathrm{min}$. GCMS analysis was performed once for each sample.

The volatiles were identified based on comparison of obtained mass spectra of samples with spectra in the WILEY mass spectra library and were confirmed by chromatography with standard chemicals. The following standard chemicals were used for identification: citronellal (Tokyo Kasei Industry Co.) and citronellol (Kanto Chemical Industry Co.).

\subsection{Statistical analysis}

Whether the number of male crossings was different among sites $\mathrm{A}-\mathrm{Z}$ was tested by a Kruskal-Wallis test. The averaged number of male passing for 25 min was compared between sites on the pass and sites off the path (sites A-E vs V$Z$ ) by a Mann-Whitney $U$ test. To examine whether daily variations in the flight activity of males were explained by air temperature and relative humidity, Pearson's correlation coefficients were calculated for those two factors and the total number of passing males at sites $A$ and $B$ for 5 min on the day. The data collected at the peak patrolling period (from 25 May to 12 June) were analyzed. The difference in response to a queen tethered at a patrolling site and at a foraging site was tested by comparing counts of males that ignored the queen using the chi-squared test of independence at the $5 \%$ significance level. Differences in male responses among queens were also examined by the same statistical test.

\section{RESULTS}

\subsection{Male behavior and flight path}

Most males were observed flying between 0.3 and $3 \mathrm{~m}$ above ground level, but some flew higher. They appeared to use particular trees or bushes as 
focal points and flew between them as described in males of other patrolling Bombus species (Svensson 1979; Goulson 2003). At the focal points, $B$. ardens ardens males briefly approached leaves by zig-zag flight and then left the tree. P. japonica, Hydrangea macrophylla, $R$. indicum, $R$. pulchrum cv. Oomurasaki, $Q$. serrata, and C. japonica were used as focal points.

The major flight paths used by many males are shown in Fig. 1. We do not know the entire flight path because individual males flew slightly different routes and dispersed in some areas. However, in other areas, flights converged on one route, and more than 40 crossings were recorded during a 5 min period on average (Table I). The males flew in both directions along the path. The number of crossings was statistically different depending on sites (sites A-Z: Kruskal-Wallis test, $\chi^{2}=45.06$, d.f. $=9, P<0.0001)$. Fewer crossings were found at sites off the path (sites $\mathrm{V}-\mathrm{Z}$ ) than at sites on the path (Table I, Fig. 1b; Mann-Whitney $U$ test, $N=5,5, Z=2.61, P<0.01)$. These results suggest that males fly along particular path(s) rather than randomly.

Since we might count the same individuals repeatedly, the actual number of individuals passing through the path should be fewer than our count.

To examine whether males make circuitous flights, six males were paint-marked at focal points, which they visited repeatedly at mean intervals of about 2-6 $\mathrm{min}$ (Table II). They always arrived at the sites from the same direction on an individual basis. Based on these results, we conclude that males make circuitous flights at the study site.

We saw eight large $B$. ardens ardens females that appeared to be queens in the study site during the 2-year observation period (2015 and 2016). Five flew across the male path and disappeared somewhere, and three burrowed into the soil, probably for hibernation. However, no mating with males was seen at the study site.

\subsection{Inter-day variation in patrolling activity}

In 2016, the first male flight at the study site was observed on 18 May. Prior to this day, no male was found at this site, even on nearby flowers foraged intensively by $B$. ardens ardens workers. After 18 May, males were often observed on flowers near the study site.

The peak patrolling activity was between late May and early June (Fig. 2), and patrolling continued until late June. Patrolling activity and air temperature or relative humidity were not significantly correlated during the peak period from 25 May to 21 June (temperature: $N=19, r=0.11$, $P>0.6, N S$; RH: $N=19, r=0.02, P>0.9, N S$; Fig. S1).

\subsection{Intra-day variation in patrolling activity}

The number of patrolling males changed with time of day in a similar manner at two sites A and B. Patrolling activity was high in the morning and late afternoon but declined at noon (Fig. 3). We first observed $B$. ardens ardens males performing scent-marking in the early morning of 25 May 2016. They landed on a leaf and walked rapidly along its edge while pressing the ventral side of the body against the leaf edge. They visited different leaves sequentially and showed the same behavior. On 10 June, we recorded the occurrence of this behavior and found that it occurred between 05:30 and 07:30 (Fig. 3b). Scent-marked plants were used as focal points later in the day.

Table I. Number of passing by males at sites on major flight path (A-E) and sites off flight path (V-Z)

\begin{tabular}{lllllll}
\hline Sites & & A & B & C & D & E \\
No. of passing & Mean \pm SD & $39.0 \pm 6.8$ & $43.3 \pm 3.3$ & $11.8 \pm 2.8$ & $17.8 \pm 4.7$ & $15.8 \pm 1.9$ \\
males/5 min & Min.-Max. & $29-47$ & $41-49$ & $9-16$ & $11-22$ & $13-18$ \\
Sites & & $\mathrm{V}$ & $\mathrm{W}$ & $\mathrm{X}$ & $\mathrm{Y}$ & $\mathrm{Z}$ \\
No. of passing & Mean $\pm \mathrm{SD}$ & $1.6 \pm 0.9$ & $0.4 \pm 0.6$ & $3.2 \pm 1.5$ & $0.6 \pm 0.9$ & $3.4 \pm 2.1$ \\
males/5 min & Min.-Max. & $1-3$ & $0-1$ & $1-5$ & $0-2$ & $0-5$ \\
\hline
\end{tabular}


Table II. Intervals of visits and directions of flights by marked males to focal point

\begin{tabular}{lllllll}
\hline $\begin{array}{l}\text { Males } \\
\text { (marking) }\end{array}$ & Date & Time & $N$ (visits) & \multicolumn{2}{l}{ Interval of visits } & $\begin{array}{l}\text { Direction } \\
\text { of flights }\end{array}$ \\
\cline { 5 - 6 } & & & & Mean \pm SD (s) & Min.-Max. (s) & \\
\hline 1 (Green) & June 20, 2016 & $14: 33-15: 29$ & 15 & $242.1 \pm 135.5$ & $101-460$ & N-S \\
2 (Orange) & June 21, 2016 & $15: 57-16: 53$ & 10 & $356.0 \pm 61.0$ & $263-427$ & N-S \\
3 (Pink) & June 2, 2017 & $15: 40-16: 01$ & 11 & $130.1 \pm 49.3$ & $69-217$ & W-E \\
4 (White) & June 3, 2017 & $9: 11-9: 46$ & 11 & $206 \pm 39.1$ & $121-268$ & N-S \\
5 (Green) & June 3, 2017 & $16: 23-17: 00$ & 16 & $148 \pm 113.6$ & $39-428$ & E-W \\
6 (Orange) & June 3, 2017 & $16: 45-17: 25$ & 10 & $268 \pm 30.6$ & $224-312$ & E-W \\
\hline
\end{tabular}

$N$ north, $S$ south, $E$ east, $W$ west

Temperature and relative humidity in the 2 days are shown in Fig. S2.

\subsection{Response to tethered queens}

Flying males often approached a queen tethered at a focal point. Some grabbed her with their legs and pressed the tip of their abdomen against her. However, such interactions were seldom observed at a foraging site (Fig. 4), although males repeatedly entered the vicinity of a queen. Chisquared tests showed that males responded by grabbing, contacting, or approaching to tethered queens significantly more frequently at the patrolling site than at the foraging site (queen A: $\chi^{2}=15.01$, d.f. $=1, P<0.001 ;$ queen B: $\chi^{2}=18.03$, d.f. $=1, P<0.001$; queen $\mathrm{C}$ : $\chi^{2}=5.35$ (with Yates' correction), d.f. $=1$, $P<0.05)$. No mating occurred at either site.

The tethered queens were killed and dissected later to examine their mating status. Queens A and $\mathrm{C}$ had empty spermatheca. The spermatheca of queen B contained sperm, indicating she had mated before capture. Despite the difference in the mating status, male responses shown in the patrol area were not statistically different among queens $\left(\chi^{2}=3.31\right.$, d.f. $\left.=6, P=0.77\right)$.

\subsection{Chemical analysis of leaves and LG}

Citronellol was detected from 8 of 13 scentmarked leaves. Citronellal was also detected in

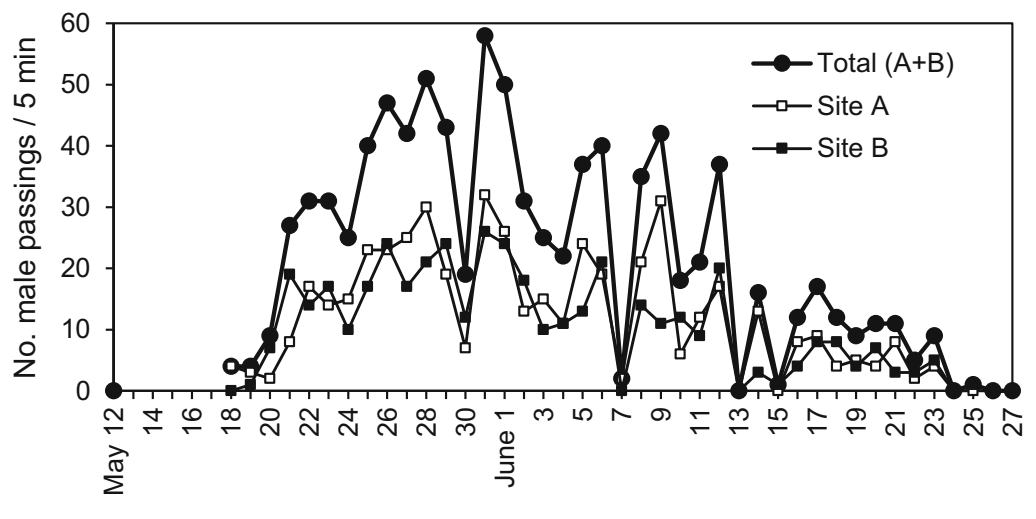

Weather

$00000000000000000000 \bullet 00000 \bullet 0000000000000$

O Sunny O Cloudy Rainy

Figure 2. Daily fluctuations in flight activity of Bombus ardens ardens males at study site in 2016. 


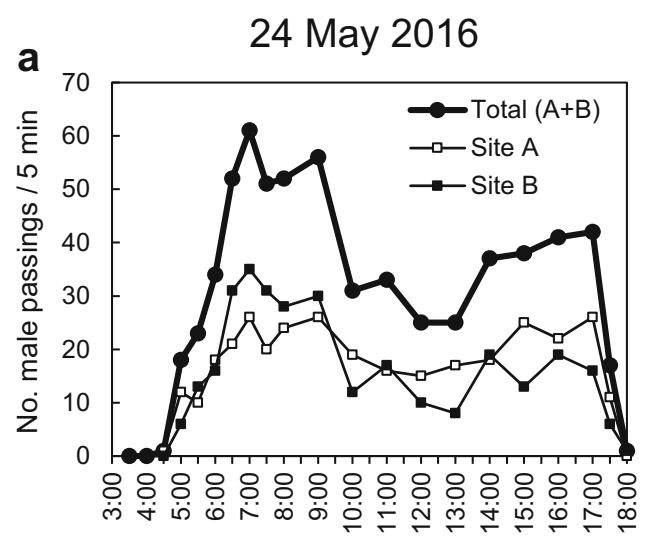

Time (JST)

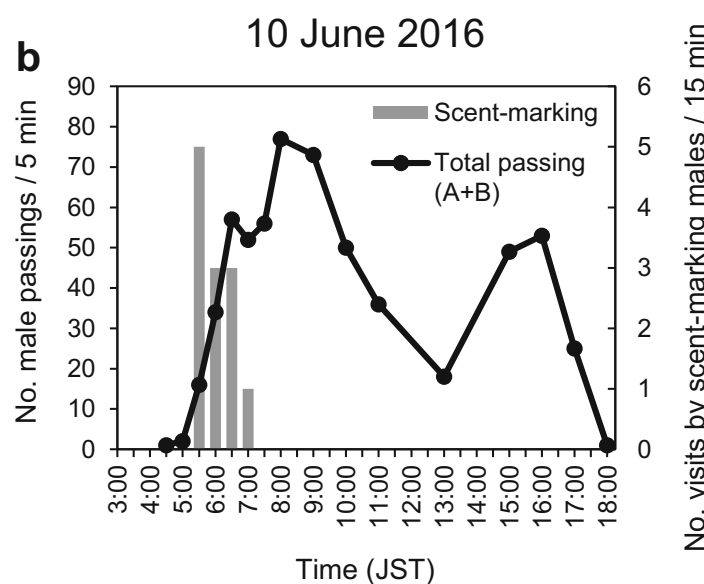

Time (JST)

Figure 3. Changes in flight activity of Bombus ardens ardens males with time of day on a 24 May and $\mathbf{b} 10$ June 2016. The number of visits by scent-marking males on four bushy trees is also shown in $\mathbf{b}$.

one of them. Those compounds were not detected from unmarked leaves $(N=13)$ (Fig. 5a, b). The total ion chromatogram for the LG confirmed citronellol and citronellal as the major and minor compounds, respectively (Fig. 5c). Citronellyl acetate, another minor compound reported by Kubo and Ono (2010), was not detected in this LG sample.

\section{DISCUSSION}

Based on previous observations, B. ardens ardens males have been thought to find mates by nest surveillance. However, we found males performing circuitous flights and scent-marking of objects on the flight path. These behaviors are consistent with premating patrolling reported in other Bombus species (Kullenberg et al. 1973; Svensson 1979; Bergman and Bergström 1997). Furthermore, we demonstrated that males performing circuitous flights were sexually motivated by presenting them with tethered queens. Free (1971) showed that Bombus pratorum males attempted mating with tethered queens at a focal point but did not respond to queens away from focal points. Males of many Bombus species patrol actively in the morning and decrease activity in the afternoon (Svensson 1979; Bertsch 1984; Goulson 2003). However, the flight activity pattern was slightly different in $B$. ardens ardens which became active again in the late afternoon; other behavioral features were the same as those in patrolling males of other species. These findings clearly indicate that the observed behavior of $B$. ardens ardens males is premating patrolling.

Males of Bombus species performing premating patrolling or perching synthesize compounds in a species-specific blend in the LG (Bergman and Bergström 1997; Hovorka et al. 1998; Luxova et al. 2004; Žáček et al. 2009). $B$. ardens ardens males produce a secretion in this organ with citronellol as the major constituent (Kubo and Ono 2010). It is believed that males deposit these substances on objects during patrolling to attract conspecific virgin queens. Although males of many Bombus species perform premating patrolling, the compounds produced in the LG have been detected on scent-marked objects only in three species, Bombus hortorum (Kullenberg et al. 1973), B. pratorum, and Bombus lapidarius (Bergman and Bergström 1997). We detected major and minor compounds (citronellol and citronellal, respectively) in the LG secretion of $B$. ardens ardens males on a known scent-marked leaf, providing additional evidence of deposition of LG secretion by males.

The male LG secretion has long been argued as serving as a sex pheromone to attract females (Kullenberg et al. 1973; Svensson 1979), but no study has assayed its activity. Kubo et al. (2017) recently used a Y-maze to demonstrate the attractiveness of citronellol to virgin $B$. ardens ardens 
a queen $\mathrm{A}$

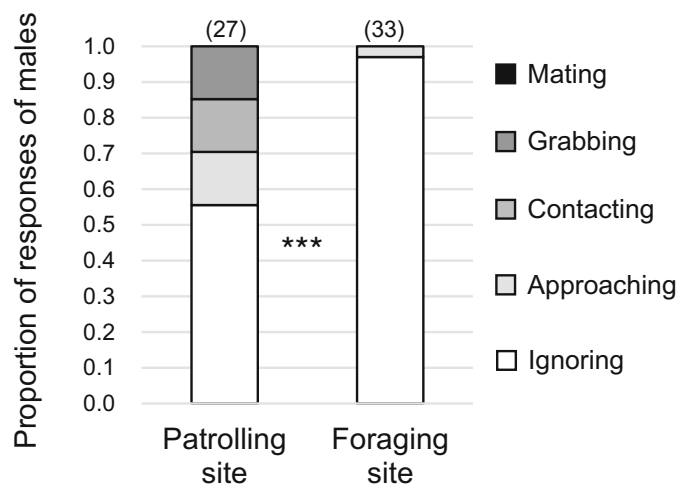

\section{b queen $\mathrm{B}$}

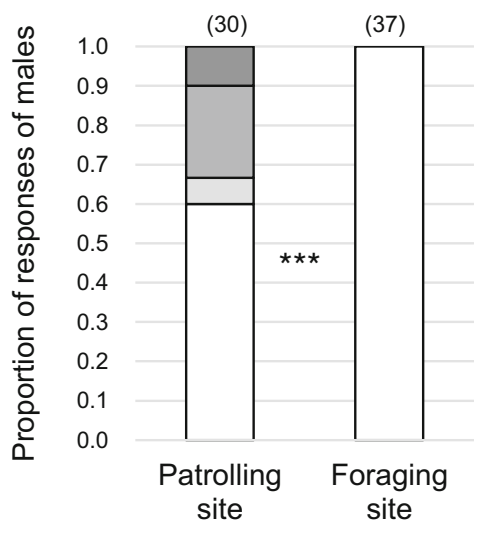

\section{c queen $\mathrm{C}$}

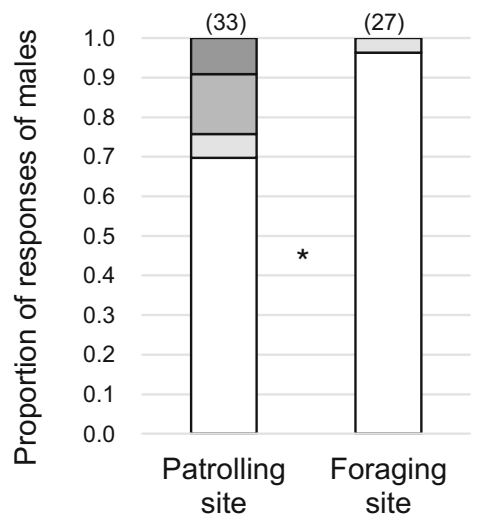

Figure 4. Responses of Bombus ardens ardens males to tethered queens at patrolling site and foraging site. Numbers in parentheses represent number of times males entered vicinity $(<50 \mathrm{~cm})$ of queen. $* P<0.05$, $* * * P<0.001$ by chi-squared test of independence. queens. Interestingly, this compound also attracted conspecific males. This finding might explain why many males fly along the same path while patrolling. Sharing of the same flight path by several males has also been reported in other species (Stiles 1976; Svensson 1979; Goulson 2003). Stiles (1976) observed groups of B. pullatus males flying together in Costa Rica and estimated numbers of 459 and 721 . Our observation showed that $B$. ardens ardens males share at least some parts of their paths. Stiles (1976) and Goulson (2003) argued that group flight increases the opportunity to attract and mate with females by accumulating more pheromone in one flight path. Svensson (1979) suggested another explanation - males might take advantage of an established flight path where other males have deposited pheromone because pheromone synthesis may be costly, and "cheating" by omission would be advantageous. A similar advantage has been suggested for a beetle with considerable differences between individuals in the amount of released pheromone (Yasui et al. 2007), but there is no study providing empirical evidence to support either hypothesis in bumblebees.

Taking the present and previous studies together (Katayama 1964; Ono and Wada 1996), it is clear that $B$. ardens ardens males have two distinct behavioral tactics (or strategies) for reproduction: nest surveillance and patrolling. Similarly, nest surveillance and patrolling by males have been reported as premating behavior in Bombus ruderarius by other researchers (Krüger 1951; Cumber 1953). Since nest surveillance may involve physical combat between males (Villalobos and Shelly 1987), individuals with disadvantageous traits for combat (e.g., small body size) might engage in patrolling. This possible alternative tactic would allow those males to secure more mating success than obtained by unsuccessful nest surveillance.

It is also possible that the same individuals may engage in both nest surveillance and patrolling. Since the patrol area of $B$. ardens ardens is in woods, males may find a conspecific nest while patrolling. In this case, they would try to mate by nest surveillance. Patrolling Pyrobombus lapponicus males are repeatedly and strongly 

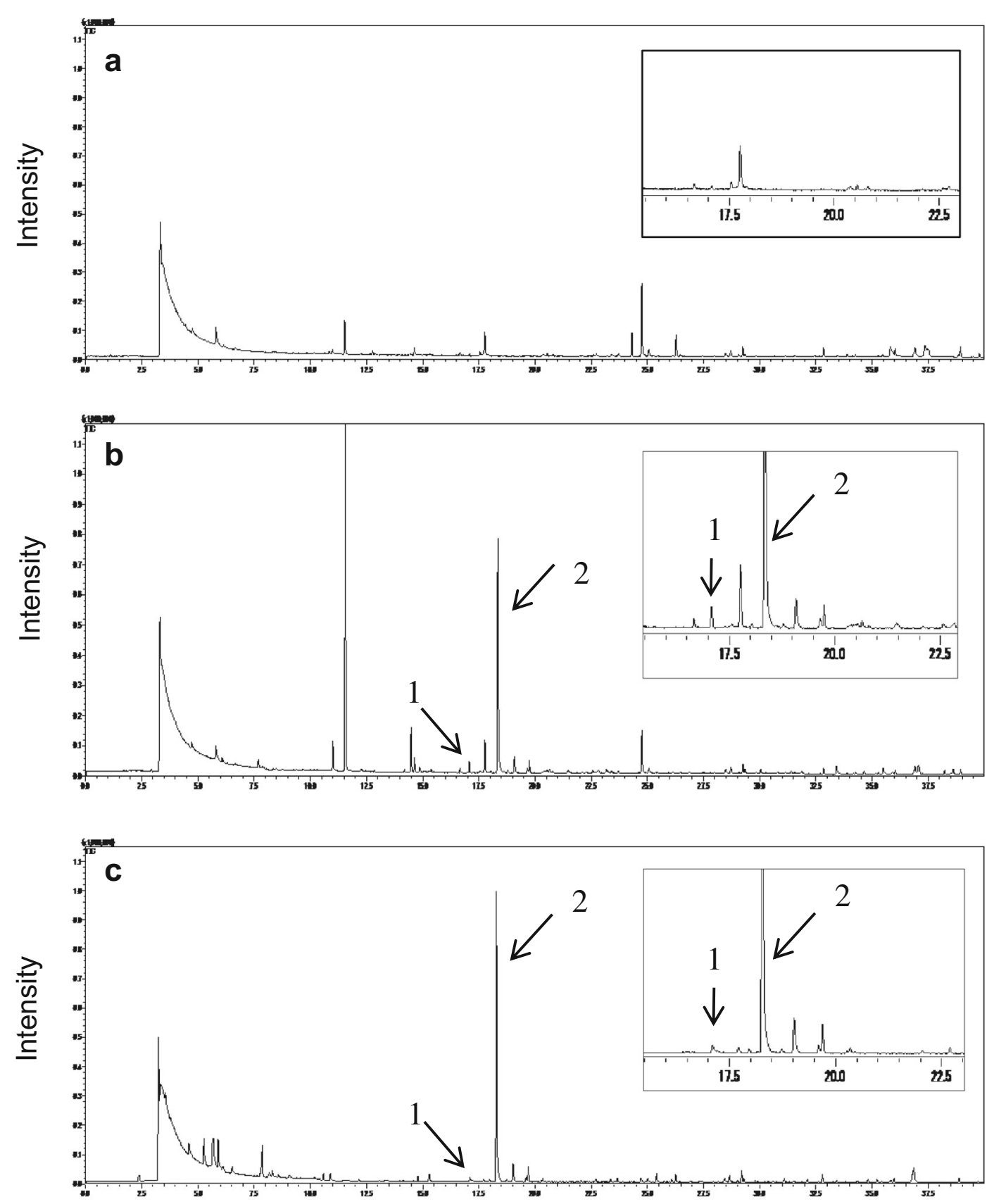

\section{Retention time (min)}

Figure 5. Examples of total ion chromatograms obtained from a unmarked leaf, $\mathbf{b}$ scent-marked leaf, and $\mathbf{c}$ labial glands of male Bombus ardens ardens. Citronellal (1) and citronellol (2). Inlets show magnified chromatograms.

attracted to a conspecific nest located on a flight path (Svensson 1979). Although neither mating nor interaction with queens was seen in his observations, males could mate in this way. Attraction 
of patrolling males to conspecific nests might result in nest surveillance in $B$. ardens ardens males.

It is unlikely that the different premating behaviors reported by previous studies and this study are attributable to a difference between local populations because Ono and Wada (1996) observed males performing nest surveillance only $500 \mathrm{~m}$ from the patrolling area of this study. However, we do not exclude the possibility that variations in male behavior are heritable and thus alternative strategies. How behavioral variations appear in bumblebee males is an interesting topic for future study.

Some premating behaviors are conspicuous and have been reported by many researchers. However, other behaviors might yet to be discovered because of inconspicuousness. The mating behaviors of B. pascuorum and Bombus lucorum have been scarcely reported although they are abundant in most parts of Europe (Goulson 2003). The present study found a new patrolling behavior in B. ardens ardens males in addition to other previously reported premating behavior, suggesting that other Bombus species may have several mating tactics.

\section{ACKNOWLEDGEMENTS}

We thank Messrs. M. Hayashi, K. Matsuo, K. Matsushima, Y. Yamaguchi, and M. Mochida for assistance in the flight path survey. We are also grateful to Dr. S. Asada who told us about seeing $B$. ardens ardens mating on campus. This study was partly supported by a Kakenhi grant [26850219] to K.H. by the Ministry of Education, Culture, Sport, Science and Technology, Japan.

\section{AUTHOR CONTRIBUTIONS}

$\mathrm{KH}$ and $\mathrm{RK}$ designed and conducted experiments. $\mathrm{KH}, \mathrm{RK}$, and MO participated in the interpretation of data. KH and RK wrote the paper. All authors read and approved the final manuscript.

Comportement de vol circulaire et de marquage olfactif chez les mâles du bourdon japonais Bombus ardens ardens : tactique alternative en vue de l'accouplement ?

Apidae / comportement pré-accouplement / stratégie reproductive / phéromone sexuelle
Patrollieren und Duftstoff-Kennzeichnungsverhalten von Drohnen der Japanischen Hummel Bombus ardens ardens : eine alternative Paarungstaktik?

\section{Drohnen / Patrollieren / Vor-Paarungsverhalten / Reproduktionsstrategie / Sex Phärhormone}

\section{REFERENCES}

Alcock J. (2013) Animal behavior: An evolutionary approach, 10th edition. Sinauer Associates, Sunderland

Bergman, P., Bergström, G. (1997) Scent marking, scent origin, and species specificity in male premating behavior of two Scandinavian bumblebees. J. Chem. Ecol. 23, 1235-1251

Bertsch, A. (1984) Foraging in male bumblebees (Bombus lucorum L.): maximizing energy or minimizing water load? Oecologia 62, 325-336

Cook, D. (1990) Differences in courtship, mating and postcopulatory behaviour between male morphs of the dung beetle Onthophagus binodis Thunberg (Coleoptera: Scarabaeidae). Anim. Behav. 40, 428-436

Cumber, R. (1953) Some aspects of the biology and ecology of humble-bees bearing upon the yields of redclover seed in New Zealand. N. Z. J. Sci. Technol. B 34, 227-240

Emlen, D. J. (1994) Environmental control of horn length dimorphism in the beetle Onthophagus acuminatus (Coleoptera: Scarabaeidae). Proc. Roy. Soc. Lond. B 256, 131-136

Forsyth, A., Alcock, J. (1990) Female mimicry and resource defense polygyny by males of a tropical rove beetle, Leistotrophus versicolor (Coleoptera: Staphylinidae). Behav. Ecol. Sociobiol. 26, 325-330

Free, J. (1971) Stimuli Eliciting Mating Behaviour of Bumblebee (Bombus pratorum L.) Males. Behaviour 40 , 55-61

Goulson, D. (2003) Bumblebees: their behaviour and ecology. Oxford University Press, New York

Gross, M. R. (1996) Alternative reproductive strategies and tactics: diversity within sexes. Trends Ecol. Evol. 11, 92-98

Hovorka, O., Urbanová, K., Valterová, I. (1998) Premating behavior of Bombus confusus males and analysis of their labial gland secretion. J. Chem. Ecol. 24, 183-193

Katayama, E. (1964) Observation on the later stage colonies of Bombus ardens Smith (Hymenoptera, Apidae). Kontyû 32 , 393-402 (In Japanese with English summary)

Kindl J., Hovorka, O., Urbanová, K., Valterová, I. (1999) Scent marking in male premating behavior of Bombus confusus. J. Chem. Ecol. 25, 1489-1500

Kokuvo, N., Toquenaga, Y., Goka, K. (2009) Effective paternity in natural colonies of Japanese native bumble bees. Ecol. Res. 24, 1111-1115 
Krüger, E. (1951) Über die Balinfiüge der Männchen der Gattungen Bombus und Psithyrus (Bombidae Hymenopt.). Z. Tierpsychol. 8, 61-75

Kubo, R., Ono, M. (2010) Comparative analysis of volatile components from labial glands of male Japanese bumblebees (Bombus spp.). Entomol. Sci. 13, 167-173

Kubo, R., Harano, K., Ono, M. (2017) Male scent-marking pheromone of Bombus ardens ardens (Hymenoptera: Apidae) attracts both conspecific queens and males. The Science of Nature. doi:10.1007/s00114-017-1493-1

Kullenberg, B., Bergström, G., Bringer, B., Carlberg, B., Cederberg, B. (1973) Observations on scent marking by Bombus Latr. and Psithyrus Lep. males (Hym., Apidae) and localization of the site of production of the secretion. Zoon Suppl. 1, 23-30

Luxova, A., Urbanova, K., Valterova, I., Terzo, M., BorgKarlson, A. (2004) Absolute configuration of chiral terpenes in marking pheromones of bumblebees and cuckoo bumblebees. Chirality 16, 228-233

Ono, M., Wada, T. (1996) Maruhanabachi no Sekai. Japan Plant Protection Association, Tokyo (In Japanese)

Shuster, S. M., Wade, M. J. (1991) Equal mating success among male reproductive strategies in a marine isopod. Nature 350 , 608-610
Stiles, E. W. (1976) Comparison of male bumblebee flight paths: temperate and tropical (Hymenoptera: Apoidea). J. Kans. Entomol. Soc. 49, 266-274

Svensson, B. G. (1979) Patrolling behaviour of bumble bee males (Hymenoptera, Apidae) in a subalpine/alpine area, Swedish Lapland. Zoon 7, 67-94

Thornhill, R. (1981) Panorpa (Mecoptera: Panorpidae) Scorpionflies: Systems for understanding resourcedefense polygyny and alternative male reproductive efforts. Annu. Rev. Ecol. Syst. 12, 355-386

Villalobos, E. M., Shelly, T. E. (1987) Observations on the behavior of male Bombus sonorus (Hymenoptera: Apidae). J. Kans. Entomol. Soc. 60, 541-548

Yasui, H., Fukaya, M., Wakamura, S., Akino, T., Yasuda, T., Kobayashi, A., Arakaki, N. (2007) Aggregation of the black chafer Holotrichia loochooana loochooana (Sawada) (Coleoptera: Scarabaeidae): Function of female pheromone and possible adaptive significance. Appl. Entomol. Zool. 42, 507-515

Žáček, P., Kalinová, B., Šobotník, J., Hovorka, O., Ptáček, V., Coppée, A., Verheggen, F., Valterová, I. (2009) Comparison of age-dependent quantitative changes in the male labial gland secretion of Bombus terrestris and Bombus lucorum. J. Chem. Ecol. 35, 698-705 